\title{
Effects of fetal genotype and uterine environment on placental development in equids
}

\author{
W. R. Allen ${ }^{1}$, J. A. Skidmore ${ }^{1}$, F. Stewart ${ }^{1}$ and D. F. Antczak ${ }^{2}$ \\ 'Thoroughbred Breeders' Association Equine Fertility Unit, Mertoun Paddocks, Woodditton Road, \\ Newmarket, Suffolk CB8 9BH, UK, and James A. Baker Institute for Animal Health, College of \\ Veterinary Medicine, Cornell University, Ithaca, NY 14853, USA
}

\begin{abstract}
Measurement of the concentrations of equine chorionic gonadotrophin (eCG) in the serum of pregnant mares and Jenny donkeys carrying normal intraspecies and hybrid interspecies pregnancies suggested that the production of this hormone may be influenced by parental gene imprinting. Specifically, a differential expression of maternal and paternal genes may control the size and secretory activity of the structures that secrete eCG, the fetal endometrial cups. However, bisection of an interspecies mule embryo followed by transfer of the resulting demi-embryos and other intact mule embryos to horse and donkey recipients resulted in striking differences in the size, secretory activity and lifespan of the endometrial cups in the two types of surrogate mother. This finding has therefore demonstrated the ability of uterine factors to alter profoundly the development and characteristic phenotype of the specialized invasive chorionic girdle portion of the equine trophoblast that gives rise to the endometrial cups.
\end{abstract}

\section{Introduction}

Equine chorionic gonadotrophin (eCG) is a highly glycosylated heterodimeric protein that expresses both FSH-like and LH-like biological activities in non-equine species (Stewart et al., 1976). It first appears in the peripheral blood of pregnant equids between 37 and 41 days after ovulation and concentrations rise steeply to a peak between days 55 and 70 . Thereafter they decline steadily until gonadotrophic activity disappears from the serum between days 100 and 140 (Cole and Hart, 1930; Day and Rowlands, 1940; Allen 1969a). The hormone is secreted by unusual fetal structures known as endometrial cups (Cole and Goss, 1943) which comprise a circle of ulcer-like protuberances in the endometrium of the gravid uterine horn. Each cup consists of a densely packed mass of large, epithelioid, binucleate cells interspersed with dilated endometrial glands and occasional blood vessels (Clegg et al., 1954; Amoroso, 1955). The large binucleate cells secrete eCG and are fetal in origin, stemming from a discrete annulate portion of the trophoblast, the chorionic girdle, which invades the overlying endometrium between days 36 and 38 after ovulation (Allen and Moor, 1972; Allen et al., 1973). As the resulting endometrial cups mature, increasing numbers of lymphocytes and other leucocytes accumulate in the endometrial stroma at the periphery of each cup. This reaction has many hallmarks of a cellular immune response to a foreign tissue graft and it appears to hasten the degeneration of the cups and their eventual desquamation from the surface of the endometrium at about day 100-140 (Allen 1975; Antczak and Allen, 1984).
In earlier reports we described the marked influence of fetal genotype on the secretion rates of eCG in pregnant mares and Jenny donkeys carrying intraspecies horse and donkey pregnancies, respectively, or interspecies hybrid mule and hinny pregnancies, respectively (Allen, 1969b; Stewart and Allen, 1981). For example, peak serum CG concentrations are high $\left(80-200 \mathrm{iu} \mathrm{ml}^{-1}\right)$ in mares carrying intraspecific horse fetuses and in Jenny donkeys carrying interspecific hinny fetuses in which the horse (Equus caballus, $2 n=64$ ) is the sire in both cases. Conversely, peak serum CG concentrations are much lower $\left(5-40 \mathrm{iu} \mathrm{ml}^{-1}\right)$ in Jenny donkeys carrying intraspecific donkey conceptuses and in mares carrying interspecific mule conceptuses in which the Jack donkey (E. asinus, $2 n=62$ ) is the sire in each case (Fig. 1).

Further experiments carried out subsequently have uncovered one reason for the big differences in endometrial cup development and eCG secretion rates. The width and overall development of the progenitor chorionic girdle appears to be closely governed by paternal genotype (Fig. 2). Thus, on horse and hinny conceptuses (horse father) a broad, thick chorionic girdle develops between days 25 and 36 which gives rise, following invasion of the maternal endometrium at day $36-38$, to large, active endometrial cups that secrete large amounts of CG into the maternal circulation. Conversely, a much narrower chorionic girdle develops on donkey and mule conceptuses (donkey father) which, in turn, results in smaller endometrial cups after invasion. The amount of eCG entering maternal blood is correspondingly less (Allen, 1975). This influence of fetal genotype on endometrial cup development has also been demonstrated in extraspecific equine pregnancies created by embryo transfer. For example, transfer of horse embryos to 


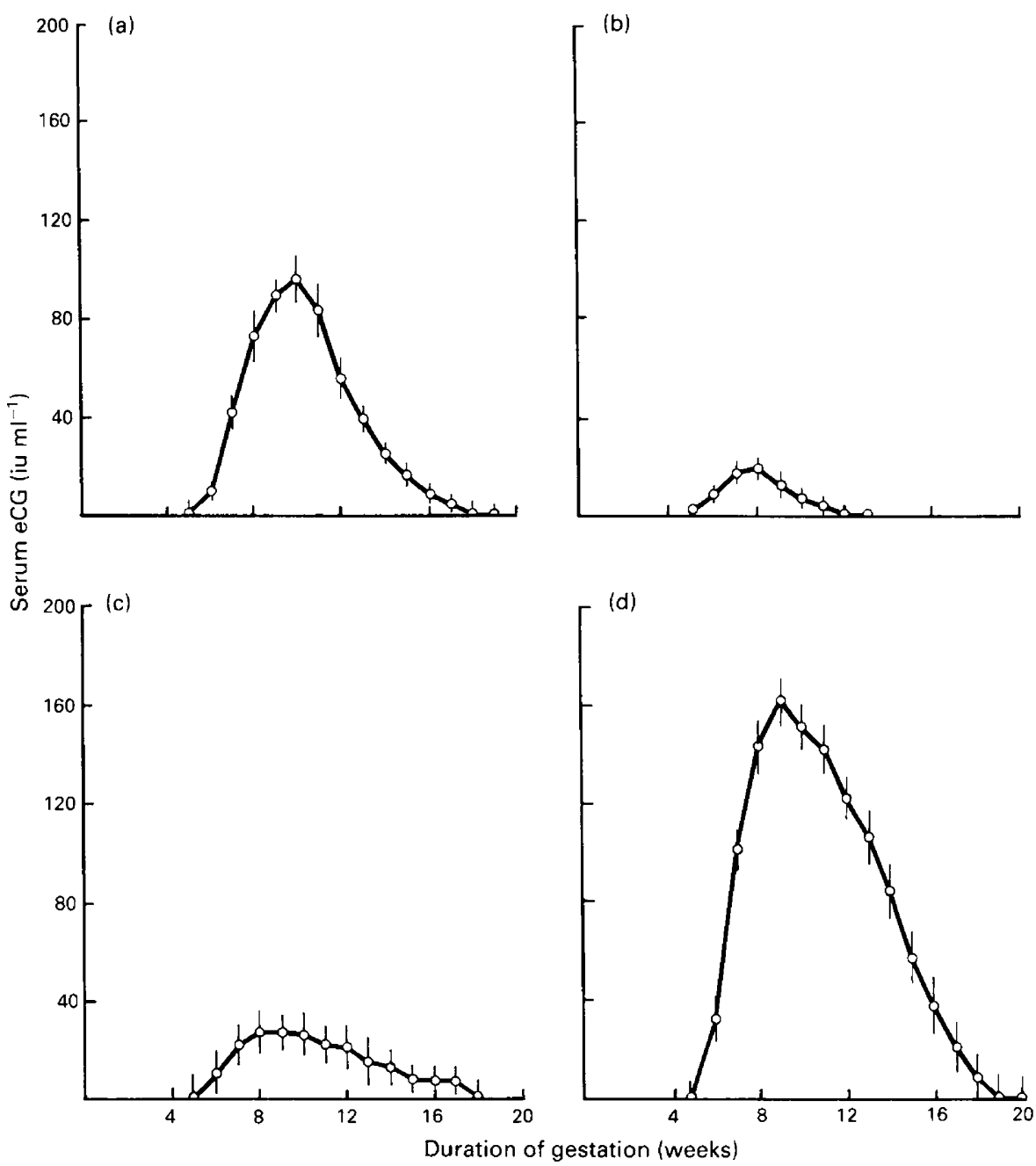

Fig. 1. Mean $( \pm \mathrm{SEM})$ concentrations of equine chorionic gonadotrophin (eCG) measured by haemagglutination inhibition assay in the serum of (a) 30 horse mares (Equus caballus, $2 n=64$ ) carrying intraspecies horse pregnancies; (b) 11 mares carrying interspecies mule pregnancies; (c) 14 Jenny donkeys ( $E$. asinus, $2 n=62$ ) carrying intraspecies donkey pregnancies and (d) 6 Jenny donkeys carrying interspecies hinny pregnancies. Peak gonadotrophin concentrations are high $\left(80-200 \mathrm{iu} \mathrm{ml}^{-1}\right)$ when the horse is the father and low $\left(5-40 \mathrm{iu} \mathrm{m} l^{-1}\right)$ when the donkey is the father (Redrawn from Stewart and Allen, 1981).

Jenny donkey recipients results in the development of broad chorionic girdles and very large and active endometrial cups, just as in donkeys carrying interspecies hinny pregnancies. Conversely, transfer of donkey embryos to horse mares is followed by the development of extremely small chorionic girdles on the donkey conceptuses which fail completely to invade the surrogate horse endometrium at day 36-38 to form endometrial cups (Allen, 1982a; Allen et al., 1987).

There has been increasing evidence in recent years which suggests that the relative contributions of homologous maternal and paternal chromosomes to development in mammals are unequal. Support for this concept of genetic imprinting has come from embryological experiments in mice (Barton et al., 1985), and from studies of genetically determined human diseases such as hydatidiform mole (see Solter, 1988; Hall, 1990 for reviews). Our findings of the apparent influence of paternal genotype on endometrial cup development and eCG secretion would seem to be a good example of parentally imprinted genes controlling placental development. To test this hypothesis further we have examined the influence of maternal uterine environment on endometrial cup development by transferring intact and bisected $F_{1}$ hybrid mule embryos to the uteri of the two parental species, the horse and donkey.

\section{Materials and Methods}

\section{Embryo transfers}

Three mule embryos were flushed non-surgically on day 6 after ovulation from the uteri of maiden pony mares that had been inseminated with Jack donkey semen on alternate days 

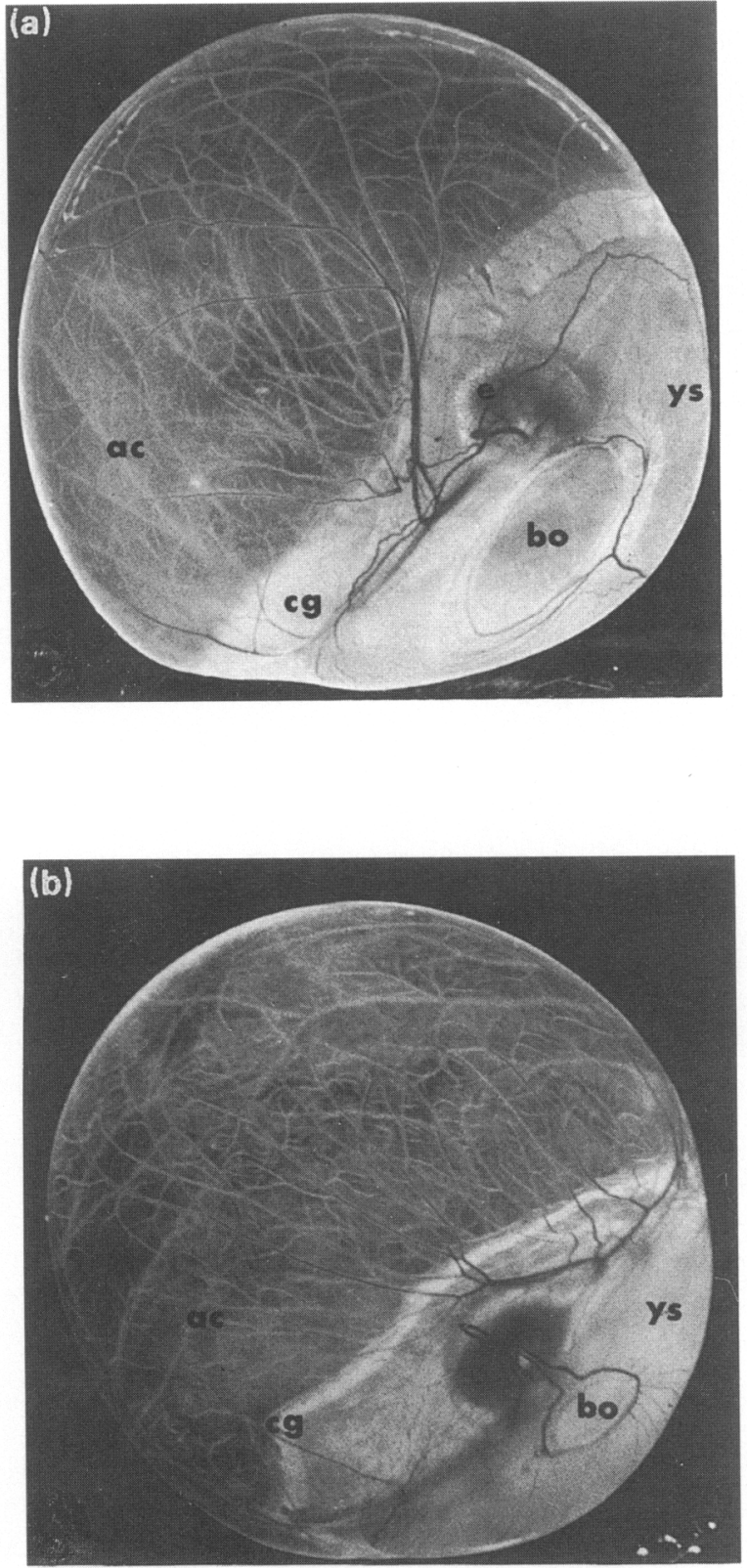

Fig. 2. (a) Intraspecies horse and (b) interspecies mule conceptuses at 35 days of gestation. The annulate chorionic girdle $(\mathrm{cg})$ of the horse conceptus, situated at the junction of the enlarging allantochorion (ac) and regressing yolk sac (ys), is much broader and thicker than that of the mule; bo: bilaminar omphalopleure, e: embryo. The diameter of the conceptus is approximately $75 \mathrm{~mm}$ at this stage of pregnancy.

during the preceding oestrus. Two embryos were already at the early expanding blastocyst stage and were transferred intact, as described by Allen (1982b), to the uteri of unmated synchronized Jenny donkey recipients. The third embryo was a compact morula and this was bisected using an extruded glass knife in a micromanipulator (Research Instruments, Devon) as described by Skidmore et al. (1989). The resulting monozygotic demiembryos were maintained in vitro for $2 \mathrm{~h}$ to allow re-compaction of the blastomeres and were then transferred surgically to unmated recipients, one to a mare and the other to a Jenny

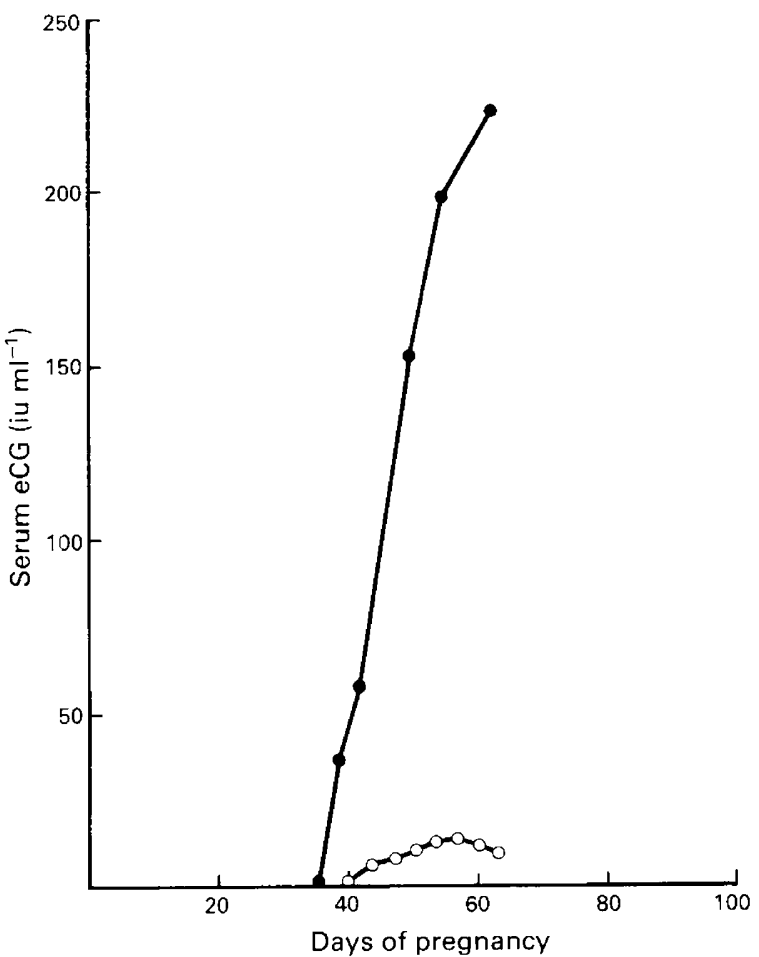

Fig. 3. Concentration of eCG measured by amplified enzyme-linked immunoassay (AELIA) in the sera of a horse mare $(\mathrm{O}-\mathrm{O})$ and a Jenny donkey ( interspecies mule embryo bisected as a morula prior to transfer.

donkey. Pregnancy in the four recipients was diagnosed initially at day 16-18, and monitored at fortnightly intervals thereafter, by transrectal realtime ultrasound scanning of the uterus (Simpson et al., 1982).

\section{eCG assay}

Peripheral blood samples were recovered three times a week from day 20 onwards from all the pregnant recipients. The serum was decanted and assayed subsequently for serum eCG concentrations in an amplified enzyme-linked immunoassay (Stanley et al., 1986) using two polyclonal anti-eCG sera raised in rabbits (MSIB and MSIIC) against highly purified extracts of eCG (MSI, $16500 \mathrm{iu} \mathrm{mg}^{-1}$; MSII, $14800 \mathrm{iu} \mathrm{mg}^{-1}$; M. J. Stewart, Cambridge) and the Second International Standard for Serum Gonadotrophin (2nd IRP-PMSG; Bangham and Woodward, 1966) as standard. The limit of sensitivity was

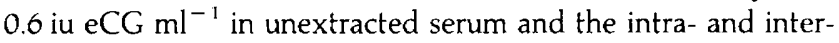
assay coefficients of variation were, respectively, 8 and $11 \%$.

\section{Tissue sampling}

Pregnancy was not interrupted in one of the Jenny donkeys that received an intact blastocyst. The other two donkey recipients were killed on days 59 (intact embryo) and 62 (bisected demi-embryo) of gestation, respectively. Their uteri were opened and, after gross examination of the endometrial cups, small pieces of cup tissue with surrounding normal 

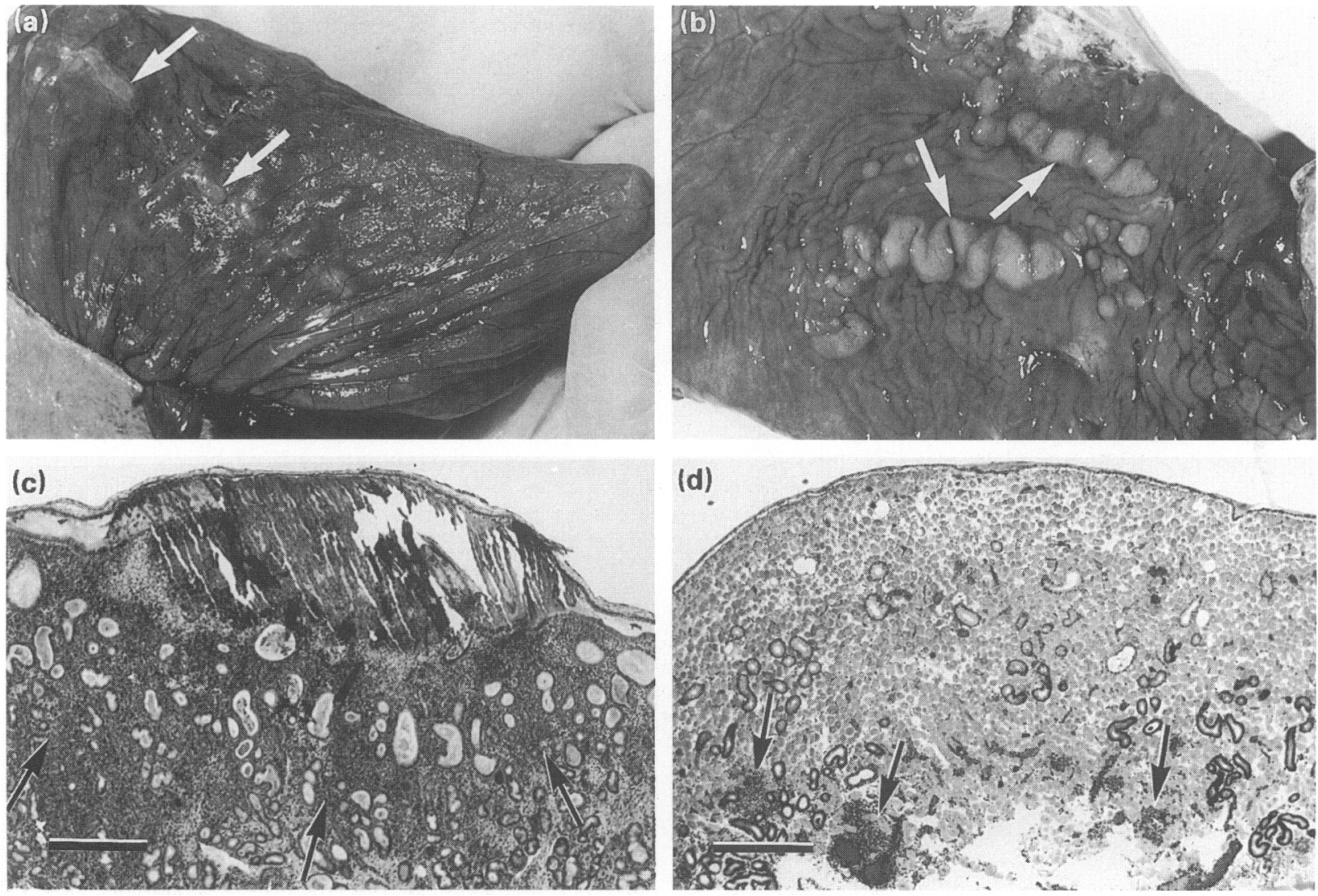

Fig. 4. Comparison of the gross ( $a$ and $b$ ) and histological ( $c$ and d) appearances of the endometrial cups at day 62 of gestation in the uteri of a horse mare ( $a$ and $c$ ) and a Jenny donkey ( $b$ and d), each carrying one half of an interspecies mule embryo bisected as a morula before transfer. The endometrial cups (arrowed) in the mare (a) are very small and narrow compared to those in the Jenny donkey (b). Histologically, the cups in the mare (c) are completely necrotic and the surrounding endometrial stroma is densely packed with maternal leucocytes (arrowed). Those in the donkey (d) are still fully viable, with the typical dense accumulation of large eCG-secreting trophoblast cells and pockets of leucocytes (arrowed) restricted to the surrounding stroma. Bar, $500 \mu \mathrm{m}$.

endometrium and attached allantochorion were fixed in Bouin's fluid for conventional histological sectioning and staining with haematoxylin and eosin. In the recipient mare carrying the other half of the bisected mule embryo, the conceptus was removed surgically on day 62 by ventral midline hysterotomy performed under general anaesthesia. The endometrial cups and the noninvasive allantochorion-endometrium interface were biopsied for histological examination.

\section{Results}

\section{eCG production}

In all three donkeys carrying transferred mule conceptuses, serum CG profiles were much more like those in donkeys carrying interspecies hinny conceptuses than the typical profiles in either mares carrying interspecies mule conceptuses or donkeys carrying intraspecies donkey conceptuses (see Fig. 1). In the donkey that continued to term, a peak concentration of 224 iu $\mathrm{ml}^{-1}$ was recorded on day 69 and CG could be detected until day 147; she gave birth spontaneously to a healthy male mule foal after 357 days of gestation. In the other two donkey recipients, serum CG concentrations had reached 164 and $224 \mathrm{iu} \mathrm{ml}^{-\mathrm{I}}$, respectively, on days 59 and 62 , and were still increasing when the animals were killed. In marked contrast, serum CG concentrations in the horse mare carrying the other demi-mule embryo rose slowly from day 37 to reach a maximum of only $16 \mathrm{iu} \mathrm{ml}^{-1}$ on day 58 . The serum CG concentrations fell again thereafter to a concentration of only $11 \mathrm{iu}$ $\mathrm{ml}^{-1}$ on day 62 when the conceptus was removed (Fig. 3).

\section{Endometrial cup development}

Gross and histological comparison of the mule endometrial cups that developed in the uteri of the two different species identified the reason for the great disparity in serum CG concentrations measured in the mare and Jenny donkey when each was carrying half of the same embryo. In the mare, the endometrial cups were typically narrow, small and flattened (Fig. 4a) and, histologically, the cup tissue was already degenerate and heavily infiltrated by maternal leucocytes (Fig. $4 \mathrm{c})$. Thus, the picture mirrored the situation in conventional interspecies mule pregnancy as described previously (Allen, 1975). In both the Jenny donkeys, by contrast, a circle of much larger, protruberant and active-looking endometrial cups was 
Table 1. Theoretical model of the control of endometrial cup development in equine pregnancies

\begin{tabular}{|c|c|c|c|c|}
\hline & Compo & ents & $\begin{array}{l}\text { Total ascribed } \\
\text { numerical }\end{array}$ & $\begin{array}{c}\text { Observed } \\
\text { size of }\end{array}$ \\
\hline & Embryonic & Uterine & value & endometrial cups \\
\hline Intraspecies pregnan & & & & \\
\hline Horse & $P^{\mathrm{H}}+M^{\mathrm{H}}$ & $+U^{\mathrm{H}}$ & +18 & Large \\
\hline Donkey & $P^{\mathrm{D}}+M^{\mathrm{D}}$ & $+U^{\mathrm{D}}$ & ${ }^{+} 14$ & Small \\
\hline Interspecies pregnan & & & & \\
\hline Mule & $P^{\mathrm{D}}+M^{\mathrm{H}}$ & $+U^{\mathrm{H}}$ & ${ }^{+} 14$ & Small \\
\hline Hinny & $P^{\mathrm{H}}+M^{\mathrm{D}}$ & $+U^{\mathrm{D}}$ & +18 & Large \\
\hline Transferred extraspe & ancies & & & \\
\hline Mule $\rightarrow$ Horse & $P^{\mathrm{D}}+M^{\mathrm{H}}$ & $+U^{\mathrm{H}}$ & ${ }^{+} 14$ & Small \\
\hline Mule $\rightarrow$ Donkey & $P^{\mathrm{D}}+M^{\mathrm{H}}$ & $+U^{\mathrm{D}}$ & +18 & Large \\
\hline Horse $\rightarrow$ Donkey & $P^{\mathrm{H}}+M^{\mathrm{H}}$ & $+U^{\mathrm{D}}$ & +22 & Very large* \\
\hline Donkey $\rightarrow$ Horse & $P^{\mathrm{D}}+M^{\mathrm{D}}$ & $+U^{\mathrm{H}}$ & +10 & Very small* \\
\hline
\end{tabular}

A. Let the embryonic derived growth factor, $P$, derived from the paternal gene, be stimulatory and have a nominal numerical value of ${ }^{+} 14$ for the horse ligand and ${ }^{+} 10$ for the donkey ligand (i.e. $P^{\mathrm{H}}={ }^{+} 14 ; P^{\mathrm{D}}={ }^{+} 10$ ).

$B$. Let the embryonic growth factor receptor, $M$, expressed from the maternal gene, be stimulatory and have nominal numerical values of ${ }^{+} 12$ for the horse and ${ }^{+} 8$ for the donkey (i.e. $M^{\mathrm{H}}={ }^{+} 12 ; M^{\mathrm{D}}={ }^{+} 8$ ).

$C$. Let the assumed uterine effect, in the form of an inhibitory factor, have nominal numerical values of -8 in the horse and ${ }^{-} 4$ in the donkey (i.e. $U^{\mathrm{H}}={ }^{-} 8 ; U^{\mathrm{D}}={ }^{-} 4$ ).

*Details in Allen (1982a).

present at the base of the gravid horn (Fig. $4 \mathrm{~b})$. Histologically, most of the eCG-secreting cup cells were still viable and there were fewer accumulated leucocytes and they remained clustered in the surrounding endometrial stroma (Fig. 4d). Thus, the picture in these two animals reflected the situation in conventional interspecies hinny pregnancy (Allen, 1975).

\section{Discussion}

Mammalian hybrids have great potential value for studying the phenomenon of gene imprinting and the already reported biochemical (Hamerton et al., 1971) and phenotypic (Tegetmeier and Sutherland, 1895) differences between the mule and its reciprocal hybrid, the hinny, may result from the action of imprinted genes (Chandley, 1989). Similarly, the major endocrinological differences exhibited by mares and Jenny donkeys when carrying interspecies mule and hinny pregnancies (see Fig. 1) would appear initially to provide a good example of imprinted genes controlling placental development and the production of placental hormones (Allen, 1969a; Stewart and Allen, 1981).

In the experiment reported here, the striking reversal of endometrial cup size and maternal serum eCG concentrations that occurred when mule embryos were made to develop in the uteri of Jenny donkeys instead of horse mares did so both with intact embryos and with a bisected demi-embryo. Hence, although only one mule embryo was bisected and transferred in the study, the results are consistent with the findings in conventional mule pregnancy and following the transfer of intact mule embryos to donkey recipients; namely, chorionic girdle and endometrial cup development are greatly enhanced in the donkey uterus compared to the horse uterus. This is consistent with normal hinny pregnancies (donkey mother) in which endometrial cup development is likewise greatly enhanced. It also accords with extraspecies donkey-in-horse pregnancy (i.e. horse uterus) in which chorionic girdle development is so diminished that endometrial cups do not form and the pregnancy usually fails before day 100 of gestation (Allen, 1982a). The horse uterus therefore appears to be inhibitory to any conceptus that contains a donkey component, whereas the donkey uterus is stimulatory to any conceptus with a horse component. This suggests that the donkey uterus is more 'permissive' than the horse uterus in terms of accepting 'foreign' inter- and extraspecies pregnancies. Thus, the apparent paternal (imprinted) effect on eCG values in intraspecies horse and donkey, and in interspecies mule and hinny pregnancies (see Fig. 1), can be modified greatly by transferring conceptuses to the 'wrong' uterus. This does not, however, eliminate the possibility that gene imprinting may influence placental development in equids, perhaps by means of reciprocal imprinting of a growth factor and its receptor, as has been demonstrated in the mouse for insulin-like growth factor 2 (Dechiara et al., 1990) and its receptor (Barlow et al., 1991).

Taking all our observations into account, and assuming that the imprinting effect involves a growth factor and its receptor, it is possible to create a model to explain our observations on the marked variations in endometrial cup development across the different types of equine pregnancy (see Table 1). If the stimulatory effects on chorionic girdle development of the proposed reciprocally imprinted growth factor ligand and receptor genes are ascribed higher numerical values in the horse than in the donkey, and if the suppressive effects of a proposed uterine factor are likewise given a more negative value in the horse 
than in the donkey, summation of the values in each type of pregnancy gives a figure that agrees closely with the observed differences in endometrial cup development and eCG secretion rate. For example, addition of the stimulatory effects of the parentally imprinted conceptus factors with the negative effects of the uterine factor gives the same total for intraspecies horse, interspecies hinny and extraspecies mule-in-donkey pregnancy, all three of which are associated with a broad and active chorionic girdle that gives rise to large endometrial cups and high serum eCG concentrations. Similarly, addition of the three values for intraspecies donkey, interspecies mule and extraspecies mule-in-horse pregnancies gives the same lower total in each case and all three types of pregnancy are associated with a narrower, less active chorionic girdle and correspondingly smaller endometrial cups. But perhaps most significant is the finding that summation of the numerical values for the transferred donkey-in-horse and horse-in-donkey pregnancy models gives a very low total for the former and a very high total for the latter. This too accords well with previous observations (Allen, 1982a) of an exceptionally small and poorly developed chorionic girdle and the complete absence of endometrial cups in the horse carrying a donkey conceptus, compared to particularly large and hyperactive endometrial cups in donkeys carrying transferred horse conceptuses.

In conclusion, it appears that development of the equine chorionic girdle and its invasion of the maternal endometrium to form gonadotrophin-secreting endometrial cups can be affected by fetal genotype and, to an even greater extent, by maternal uterine environment. Awareness of these interacting factors has come about as a result of the apparently unique ability of equids to conceive a wide range of interspecific hybrid fetuses and to carry true xenogeneic extraspecies pregnancies created by embryo transfer.

This work was financed by The Thoroughbred Breeders' Association and the Horserace Betting Levy Board, with partial support from grants to D. F. Antczak from USDA, NIH and The Dorothy Russell Havemeyer Foundation Inc. We are grateful to A. McLaren and A. Surani for heipful discussions.

\section{References}

Allen WR (1969a) The immunological measurement of pregnant mare serum gonadotrophin Journal of Endocrinology 43 593-598

Allen WR (1969b) Factors influencing pregnant mare serum gonadotrophin production Nature $22364-66$

Allen WR (1975) The influence of fetal genotype upon endometrial cup development and PMSG and progestagen production in equids Joumal of Reproduction and Fertility Supplement 23 405-413

Allen WR (1982a) Immunological aspects of the endometrial cup reaction and the effects of xenogeneic pregnancy in horses and donkeys journal of Reproduction and Fertility Supplement 31 57-94

Allen WR (1982b) Embryo transfer in the horse. In Mammalian Egs Transfer pp 135-154 Ed. CE Adams. CRC Press, Florida
Allen WR and Moor RM (1972) The origin of the equine endometrial cups. I. Production of PMSG by fetal trophoblast cells Journal of Reproduction and Fertility 29 313-316

Allen WR, Hamilton DW and Moor RM (1973) The origin of the equine endometrial cups. II. Invasion of the endometrium by trophoblast Anatomical Record 177 485-502

Allen WR, Kydd JH, Boyle MS and Antczak DF (1987) Extra-specific donkey-inhorse pregnancy as a model of early fetal death Journal of Reproduction and Fertility Supplement 35 197-209

Amoroso EC (1955) The endocrinology of pregnancy British Medical Bulletin 17 $117-125$

Antczak DF and Allen WR (1984) Invasive trophoblast in the genus Equus. Annales d'Immunologie-Institut Pasteur 135D 325-331, 341-342

Bangham DR and Woodward PM (1966) The second international standard for serum gonadotrophin Bulletin of the World Health Organization 35 761-773

Barlow DF, Stöger R, Herrmann BG, Saito K and Schweifer N (1991) The mouse insulin-like growth factor type-2 receptor is imprinted and closely linked to the Tme locus Nature 349 84-87

Barton SC, Surani MAH and Norris ML (1985) Roles of paternal and maternal genomes in mouse development Nature 311 374-376

Chandley AC (1989) Why don't the mule and hinny look alike? Quarterly Joumal of the British Mule Society 43 7-10

Clegg MT, Boda JM and Cole HH (1954) The endometrial cups and allantochorionic pouches in the mare with emphasis on the source of equine gonadotropin Endocrinology 54 448-463

Cole HH and Goss $\mathbf{H}$ (1943) The source of equine gonadotrophin. In Essays in Biology in Honour of Herbert M. Evans pp 107-119. University of California Press, Berkeley

Cole HH and Hart GH (1930) The potency of blood serum of mares in progressive stages of pregnancy in effecting the sexual maturity of the immature rat American Joumal of Physiology 93 57-68

Day FT and Rowlands IW (1940) The time and rate of appearance of gonadotrophin in the serum of pregnant mares Journal of Endocrinology 2 255-261

Dechiara TM, Efstratiadis A and Robertson EJ (1990) A growth-deficiency phenotype in heterozygous mice carrying an insulin-like growth factor 2 gene disrupted by targeting Nature 345 78-80

Hall JG (1990) Genetic imprinting: review and relevance to human diseases American Journal of Human Genetics 46 857-873

Hamerton JL, Richardson BJ, Gee PA, Allen WR and Short RV (1971) Nonrandom X-chromosome expression in female mules and hinnies Nature 232, 312-315

Simpson DJ, Greenwood RES, Ricketts SW, Rossdale PD, Sanderson MW and Allen WR (1982) Use of ultrasound echography for early diagnosis of single and twin pregnancy in the mare Journal of Reproduction and Fertility Supplement $32431-439$

Skidmore J, Boyle MS, Cran D and Allen WR (1989) Micromanipulation of equine embryos to produce monozygotic twins Equine Veterinary Journal Supplement 8 126-128

Solter D (1988) Differential imprinting and expression of maternal and paternal genomes Annual Review of Genetics 22 127-146

Stanley CJ, Paris F, Webb AE, Heap RB, Ellis ST, Hamon M, Worsfold A and Booth JM (1986) Use of a new and rapid milk progesterone assay to monitor reproductive activity in the cow Veterinary Record 118, 664-667

Stewart F and Allen WR (1981) Biological functions and receptor binding activities of equine chorionic gonadotrophins Journal of Reproduction and Fertility 62 527-536

Stewart F, Allen WR and Moor RM (1976) Pregnant Mare Serum Gonadotrophin: ratio of follicle stimulating hormone and luteinizing hormone activities measured by radioreceptor assay Journal of Endocrinology 71 371-382

Tegetmeier WB and Sutherland CL (1985) Horses, Asses, Zebras, Mules and Mule Breeding Horace Cox, London 